OPEN ACCESS

Edited by:

Cliff Ross,

University of North Florida,

United States

Reviewed by:

Patricia González-Díaz,

University of Havana, Cuba

Savanna Barry,

University of Florida, United States

${ }^{*}$ Correspondence:

Crystal J. McRae

crystal.j.mcrae@gmail.com

${ }^{\dagger}$ These authors have contributed equally to this work and share first

authorship

Specialty section:

This article was submitted to

Coral Reef Research

a section of the journal

Frontiers in Marine Science

Received: 28 May 2021

Accepted: 29 July 2021

Published: 06 September 2021

Citation:

McRae CJ, Mayfield $A B$

Huang WB, Côté IM and Fan TY

(2021) Contrasting Proteomic Responses of Adult and Larval Coral

to High Temperatures.

Front. Mar. Sci. 8:716124.

doi: 10.3389/fmars.2021.716124

\section{Contrasting Proteomic Responses of Adult and Larval Coral to High Temperatures}

\author{
Crystal J. McRae ${ }^{1,2 * t}$, Anderson B. Mayfield ${ }^{3,4,5 t}$, Wen-Bin Huang ${ }^{2}$, Isabelle M. Côté ${ }^{1}$ and \\ Tung-Yung Fan ${ }^{3,6}$ \\ ${ }^{1}$ Department of Biological Sciences, Simon Fraser University, Burnaby, BC, Canada, ${ }^{2}$ Department of Natural Resources \\ and Environmental Studies, National Dong Hwa University, Hualien, Taiwan, ${ }^{3}$ National Museum of Marine Biology \\ and Aquarium, Pingtung, Taiwan, ${ }^{4}$ Cooperative Institute for Marine and Atmospheric Studies, University of Miami, Miami, FL, \\ United States, ${ }^{5}$ Atlantic Oceanographic and Meteorological Laboratory, National Oceanic and Atmospheric Administration \\ (NOAA), Miami, FL, United States, 6 Institute of Marine Biology, National Dong Hwa University, Pingtung, Taiwan
}

Climate change-induced increases in seawater temperature continue to impact coral reef ecosystems globally. There is a consequent need to characterize the responses of corals to thermal stress to understand the molecular processes underpinning these responses and identify hallmarks of resilience. Here we used an iTRAQ approach to compare the proteomes of adult corals (Pocillopora acuta) that had been thermally conditioned at a control $\left(26^{\circ} \mathrm{C}\right)$ or elevated temperature $\left(29.5^{\circ} \mathrm{C}\right)$ for three reproductive cycles, as well as the larvae released by these corals. We found that larvae responded more to high-temperature exposure at the protein level than their parents and that different proteins were affected between life stages; a single protein was up-regulated at high temperatures in both adults and their offspring, and its identity is currently unknown. Similarly, different cellular pathways were affected by high-temperature exposure between the coral hosts and their dinoflagellate endosymbionts; proteins involved in translation and protein trafficking were most likely to be affected by high-temperature exposure in the former, with photosynthesis being the most thermo-sensitive process in the latter. Collectively, these findings highlight the importance of considering both life stage and the composition of the coral holobiont when using molecular-scale data to model cellular processes associated with responses to future ocean warming.

Keywords: acclimation, climate change, coral, life-stage effects, proteomics

\section{INTRODUCTION}

Coral reefs are threatened globally by the rising seawater temperatures associated with climate change (Hoegh-Guldberg et al., 2017) yet some coral populations have demonstrated a remarkable degree of thermal resilience [e.g., corals from thermally variable reefs: Barshis et al. (2013) and Safaie et al. (2018); but see also Klepac and Barshis (2020)]. Plasticity in coral response to elevated temperatures has led to the exploration of techniques targeting the active enhancement of coral thermal tolerance (e.g., assisted evolution; van Oppen et al., 2015). Since initial inquiry into the capacity of transgenerational acclimation in corals (Putnam and Gates, 2015), several studies have examined the effects of adult conditioning (temperature and/or $p \mathrm{CO}_{2}$ ) on offspring performance 
(e.g., Bellworthy et al., 2019; Putnam et al., 2020). However, the potentially diverse proteomic responses across coral life stages and between coral hosts and their dinoflagellate endosymbionts remain uncharacterized. We consequently sought to explore the proteomic effects of thermal conditioning using colonies of the brooding coral Pocillopora acuta that had been exposed to either control $\left(26^{\circ} \mathrm{C}\right)$ or experimentally elevated temperatures $\left(29.5^{\circ} \mathrm{C}\right)$ for three reproductive cycles. We specifically employed a quantitative proteomics approach known as "isobaric tags for relative and absolute quantification" (iTRAQ; SCIEX) to assess cellular strategies for responding to high temperature by directly targeting the molecules that enact physiological changes in coral and Symbiodiniaceae cells.

\section{MATERIALS AND METHODS}

\section{The Experiment}

Colonies of the reef-building coral $P$. acuta $(n=24)$, which release larvae hosting symbiotic dinoflagellates (i.e., vertical transmission) monthly (Fan et al., 2017), were collected from Outlet reef $\left(21^{\circ} 93^{\prime} 20^{\prime \prime} \mathrm{N}, 120^{\circ} 74^{\prime} 46^{\prime \prime} \mathrm{E}\right)$ in Nanwan Bay, Southern Taiwan. Nanwan Bay has a highly variable thermal regime due to frequent upwelling events (Lee et al., 1997), and Outlet reef has higher maximum temperatures than nearby reefs due to the influence of warm water effluent from an adjacent nuclear power plant (Keshavmurthy et al., 2014). The unique thermal characteristics of this region have been linked to higher associations with thermally tolerant Symbiodiniaceae lineages at Outlet reef (Carballo-Bolaños et al., 2019; Keshavmurthy et al., 2014), and molecular mechanisms of thermal acclimation have been documented in adult corals (Mayfield et al., 2012, 2013) in Nanwan Bay.

Collected colonies were held in individual tanks within a natural seawater flow-through system at the National Museum of Marine Biology and Aquarium at either a control $\left[26.2^{\circ} \mathrm{C} \pm 0.4^{\circ} \mathrm{C}\right.$ (mean \pm standard deviation for these and all other error terms unless stated otherwise)] or heated $\left(29.7^{\circ} \mathrm{C} \pm 0.3^{\circ} \mathrm{C}\right)$ temperature from March to May 2017 [see McRae et al. (2021) for experiment details], and released larvae were collected each month. The high-temperature value was chosen based on our prior work showing it to be sub-lethal to corals over a 9-month study, yet high enough to elicit fundamental cellular changes (Mayfield et al., 2013, 2014). During the third reproductive cycle (May 2017), we immersed a branch $(\sim 2 \mathrm{~cm}$ in length) from each control and high-temperature colony, as well as 20 of their respective larvae in TRIzol $^{\circledR}$ (Life Technologies) and froze them at $-80^{\circ} \mathrm{C}$ prior to protein extraction (see below). We selected a subset, comprised of one adult and its associated larvae from each treatment, in May 2017 to assess protein responses across coral life stages. The maximum quantum yield of photosystem II (Fv/Fm) for the two selected colonies was similar at the time of sampling (control $=0.60 \pm 0.004$, heated $=0.59 \pm 0.062$ ), but their reproductive investment (timing, fecundity, and larval size) varied (Supplementary Figures 1-3); these data are a subset of the colonies presented in McRae et al. (2021). Larvae from both of the subset colonies were competent at release and able to settle at both control and high temperatures. Our sample size was limited because of the high analysis cost $(\sim 600 \mathrm{USD} /$ sample $)$ coupled with the fact that, at the time of sampling, only four samples could be analyzed in parallel (i.e., in a comparative framework) using iTRAQ technology.

\section{Protein Extractions, Liquid Chromatography, and Mass Spectrometry}

Adult ( $n=2$ colonies) and larval ( $n=2$ larval batches) proteins were extracted following Mayfield et al. (2011) and Putnam et al. (2013), respectively (see details in the Supplementary Material). Detergent-free, iTRAQ-labeled peptides were mixed with formic acid ( $0.1 \%$ final concentration) prior to nano-liquid chromatography on an Ultimate 3,000 RSLC system (Dionex) equipped with a C18 column (Acclaim PepMap RSLC, $75 \mu \mathrm{m} \times 150 \mathrm{~mm} \times 2 \mu \mathrm{m}, 100 \AA)$ using $0.1 \%$ formic acid and $95 \%$ acetonitrile $+0.1 \%$ formic acid as the mobile phases. Full mass spectrometry (MS) scans were performed across five different $\mathrm{m} / \mathrm{z}$ ranges (300-2,000, 300-600, $600-800,800-1,200$, and $1,200-2,000)$ on a $\mathrm{Q}$ Exactive $^{\mathrm{TM}}$ mass spectrometer [Thermo-Fisher Scientific (TFS)] operated in HCD fragmentation mode. The 10 most intense ions from each scan were subjected to fragmentation for MS/MS spectra. The 61,375 spectra were processed into peak lists by Proteome Discoverer 1.4 (TFS), distilled into a single MGF data file with Mascot Distiller (ver. 2.6.0; Matrix Sciences), and made publicly available on the MassIVE and Proteome Xchange data repositories.

\section{iTRAQ Data Analysis}

Mascot's MS/MS ion search was used to query the MGF file against three nucleic acid databases: the Pocillopora damicornis genome (Cunning et al., 2018), the Southern Taiwan-based P. acuta-Cladocopium sp. holobiont transcriptome (Mayfield et al., 2014), and the Breviolum sp. genome (Shoguchi et al., 2013) (see Supplementary Material for search parameters). A false discovery rate of 0.01 was set for protein identification. As a second quality control (QC) criterion, we required that at least two peptides mapped to the same protein. Predicted protein sequences were BLASTed (tBLASTn) against the holobiont transcriptome hosted on the interactive $P$. acuta transcriptome server ${ }^{1}$ to confirm identity. All data featured in analyses have been included in the Supplementary Material.

iTRAQ label 114 (heated adult) was set as the denominator and used to generate the following ratios: 115/114 (heated larvae/heated adult), 116/114 (control adult/heated adult), and $117 / 114$ (control larvae/heated adult). Data were normalized to the average intensity ratio and used in two primary comparisons: high-temperature vs. control (for each life stage and pooled across both), and larvae vs. adults (for each temperature and pooled across both). Due to our small samples size, we took a conservative approach and only proteins that differed in relative concentration by $>2$-fold for any comparison were considered

\footnotetext{
${ }^{1}$ http://symbiont.iis.sinica.edu.tw/coral_pdltte/static/html/index.html\#home
} 
"differentially concentrated proteins" (DCPs). Annotation for these DCPs was acquired from the aforementioned P. acuta transcriptome server to make inferences into probable protein function, and gene ontology groups were used to cluster proteins into pathways (e.g., metabolism). The compartmental breakdown with respect to host and dinoflagellate was assessed across the entire dataset, and within each group of DCPs. $X^{2}$ tests were used to compare (1) the percentage of proteins that were differentially concentrated between the two life stages and between the eukaryotic compartments of the mutualism (i.e., host corals vs. dinoflagellate endosymbionts) and (2) the DCP breakdowns for each comparison type listed above against the entire proteome. Statistical analyses were carried out with $\mathrm{JMP}^{\circledR}$ Pro (ver. 14 or 15) at an alpha level of 0.01 .
A All sequenced proteins $(\mathrm{n}=601)$

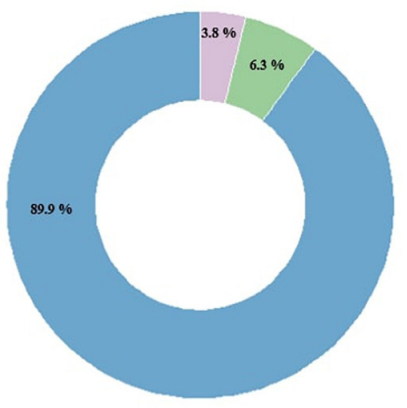

C Groupings of DCPs

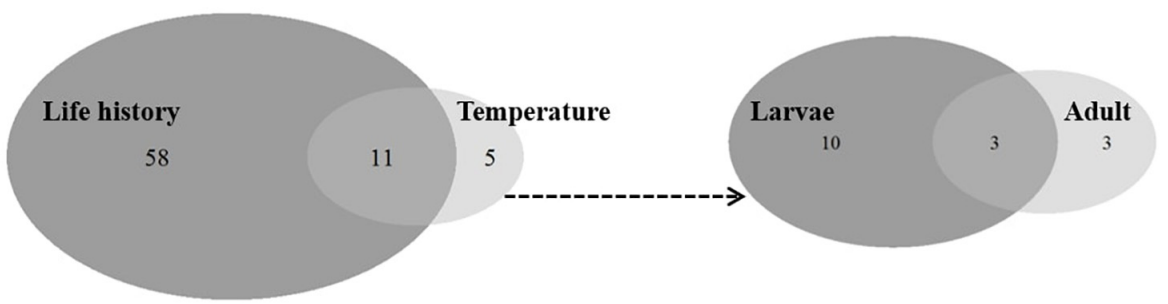

B $\quad \operatorname{DCPs}(\mathrm{n}=74)$

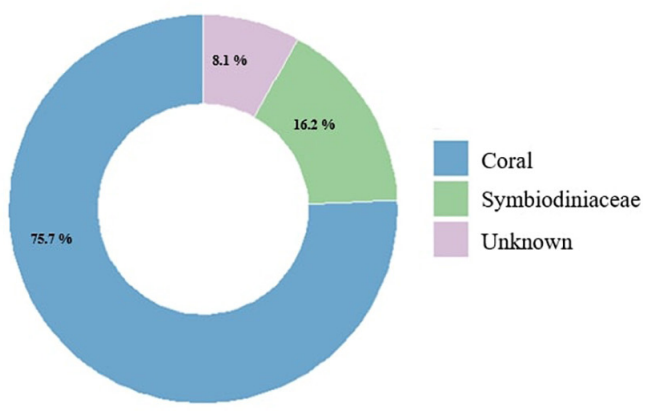

D Temperature-responsive DCPs by life stage

FIGURE 1 | Pocillopora acuta proteomic response to elevated temperature. (A) Compartmental breakdown of the source of all sequenced proteins $(n=601)$ compared to (B) differentially concentrated proteins (DCPs) $(n=74)$. (C) Venn diagram of DCPs by life stage and temperature and (D) temperature-related DCPs in adult and larval corals.

TABLE 1 | Proteins differentially concentrated across temperatures in adult and larval Pocillopora acuta corals.

\begin{tabular}{|c|c|c|c|c|}
\hline Protein accession (NCBI) & Protein name & Protein function & Compartment & Concentration trend \\
\hline gil 1500199810 & Histone & Transcription & Host & Control > high* \\
\hline gi| 1500190340 & Histone $\mathrm{H} 1 / 5$ & Transcription & Host & Control > high* \\
\hline gi| 1524872764 & Histone & Transcription & Host & Control > high* \\
\hline gil 1500200680 & Large subunit ribosomal protein I35e & Translation & Host & Control > high* \\
\hline gi| 1500189963 & Neuronal pentraxin & Immunity & Host & Control $>$ high, larvae $>$ adult \\
\hline gil 1524900419 & Unknown & Unknown & Host & High $>$ control, larvae $>$ adult \\
\hline gil 1500211279 & Translocon-associated protein subunit beta & Protein trafficking & Host & High $>$ control, larvae $>$ adult \\
\hline gil 1500211780 & Concanavalin A-like lectin/glucanase & Cell adhesion & Host & High $>$ control, larvae $>$ adult \\
\hline gil 1524887799 & TPR/MLP1/MLP2-like protein & Protein trafficking & Host & High $>$ control, larvae $>$ adult \\
\hline gi| 356591896 & Peridinin-chlorophyll a-binding protein & Photosynthesis & Sym & Control $>$ high, adult $>$ larvae \\
\hline gb| OLQ06705.1 & Chloroplast ATP synthase & Metabolism & Sym & Control $>$ high, adult $>$ larvae \\
\hline gb| OLQ02953.1 & Unknown & Unknown & Sym & High $>$ control $^{*}$ \\
\hline gi| 1500209163 & Collagen alpha-1(II) chain-like & Structural & Unknown & High $>$ control, larvae $>$ adult \\
\hline gi| 1500201742 & Unknown & Unknown & Unknown & High $>$ control, larvae $>$ adult \\
\hline gil 1500201741 & Unknown & Unknown & Unknown & High $>$ control, larvae $>$ adult \\
\hline de novo.id25751.tr59102 & Unknown & Unknown & Unknown & High $>$ control, larvae $>$ adult \\
\hline
\end{tabular}

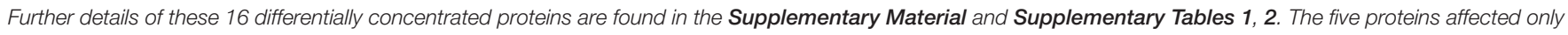
by temperature, and not life stage, are marked by asterisks (*). The three proteins affected by temperature in both life stages are in bold font. Sym, Symbiodiniaceae. 


\section{RESULTS AND DISCUSSION}

Of the 601 proteins that passed QC (mean sequencing coverage $\pm S D=12.3 \pm 11.3 \%$; Supplementary Table 1 and Supplementary Material), 540 (90\%) were from the host, with only 38 (6\%) from the endosymbiotic dinoflagellates (Figure 1A). The origin of the remaining 23 proteins (4\%) could not confidently assigned. This $\sim 540: 38(\sim 14: 1)$ host:endosymbiont ratio is significantly higher ( $X^{2}$ test, $\left.p<0.0001\right)$ than the $\sim 2: 1$ adult biomass ratio of this coral (deduced by Mayfield et al., 2014) and could reflect an annotation bias associated with the fact that the nucleic acid databases queried were not derived from the same samples whose proteomes were analyzed herein; this idea is explored in greater detail in the Supplementary Material.

When looking at the 74 DCPs obtained across all comparisons $(\sim 12 \%$ of the proteome; Supplementary Table 2$)$, the compartmental breakdown was also skewed in favor of the host (76\% of DCPs); only 12 dinoflagellate DCPs were uncovered (16\% of DCPs) (Figure 1B). When compared to all sequenced proteins, this represents an enrichment of endosymbiont DCPs ( $6 \%$ of all proteins vs. $16 \%$ of DCPs; Fisher's exact test, $p<0.01$ ). Furthermore, $10 \%$ and $32 \%$ of the host and dinoflagellate proteins, respectively, were differentially concentrated across samples $\left(X^{2}{ }_{1}=987, p<0.001\right)$. When considering only the temperature-responsive proteins, six of 540 host coral proteins (1\%) and three of 38 endosymbiont proteins (8\%) were affected by temperature. This statistically significant $\left(X^{2}{ }_{1}=5.9, p=0.01\right)$ compartmental difference suggests that the dinoflagellate proteome is more thermo-responsive than that of their coral hosts. The same result was observed in previous mRNA(Mayfield et al., 2014) and protein- (Mayfield et al., 2018) based works with adult specimens of this coral species.

Of the 74 DCPs, 58 and five were affected by life stage and temperature, respectively (with 11 affected by both; Figure 1C).

\section{Life stage effects}

A

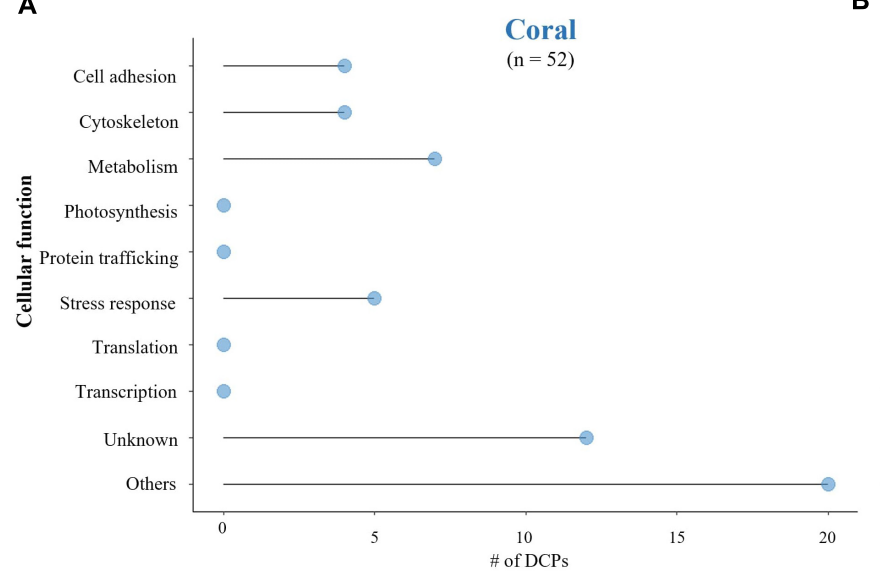

B

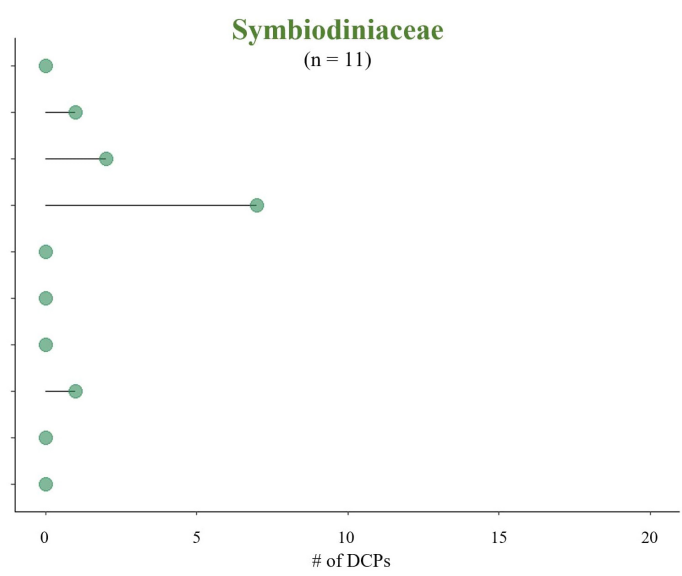

Temperature effects
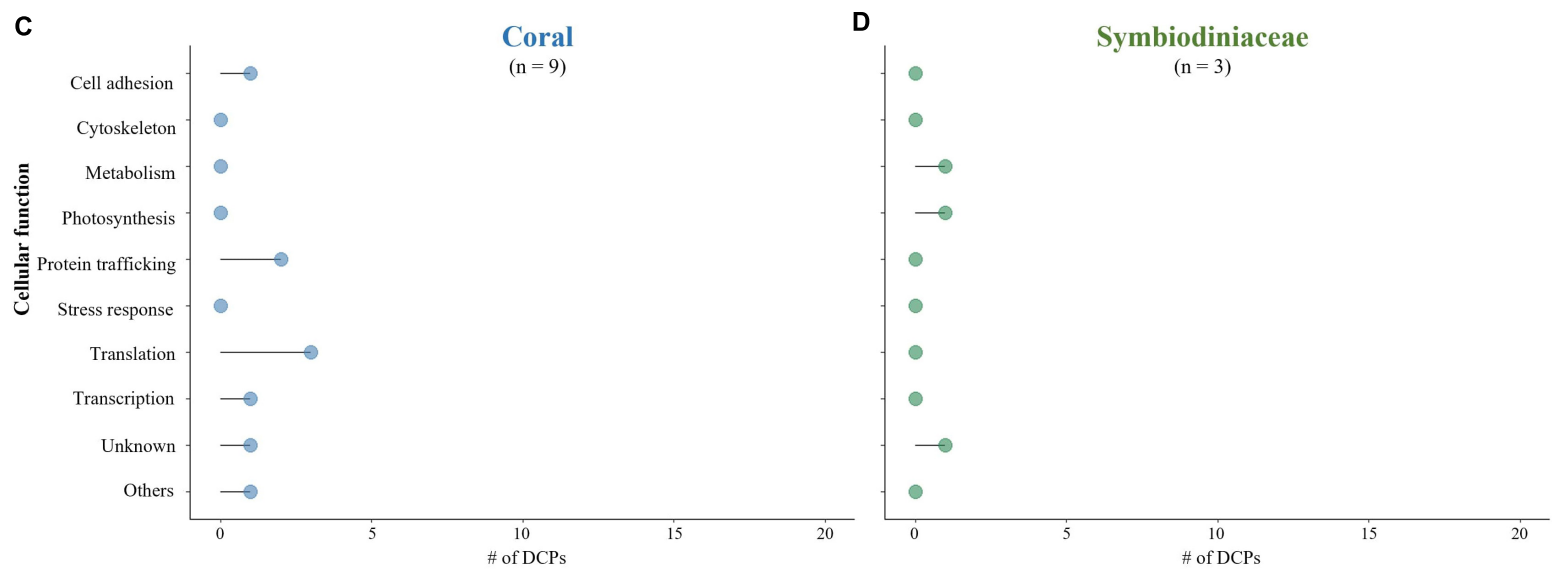

FIGURE 2 | Comparison of differentially concentrated proteins (DCPs) and their associated cellular function in the Pocillopora acuta coral host (A,C) and

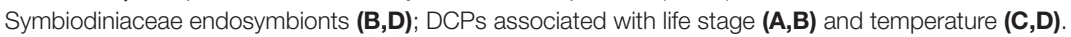


Ten of the 16 temperature-responsive proteins (Table 1) were documented only in the larvae; only three proteins were affected by temperature in adults and not in larvae (with three affected by high-temperature exposure in both) (Figure 1D). Only one protein (de novo.id25751.tr59102) was up-regulated at high temperatures in both adults and their larvae, though the identity of this 376-amino acid (AA) protein could not be resolved using traditional bioinformatics approaches. Given the fact that it was the only protein of more than 600 sequenced that increased significantly in concentration at high temperatures in both adult corals and their offspring, identifying it should be a priority for future research. This protein could perhaps serve as a biomarker for sub-lethal temperature stress.

A Symbiodiniaceae chloroplast ATP synthase and a host large subunit ribosomal protein (L35e) were both down-regulated at high temperatures in both life stages (Table 1). The former is directly responsible for establishing ATP levels in the chloroplast, and its down-regulation at elevated temperatures may signify that chloroplast metabolism was impacted. In plants, expression is essentially completely halted in the dark such that ATP hydrolysis ceases; this is presumably due to the need to conserve ATP (Kohzuma et al., 2017). This down-regulation of chloroplast ATP synthase might therefore represent an ATP conservation strategy occurring at sub-lethal, but still potentially stressinducing temperatures.

Different cellular pathways were affected by life stage (Figures 2A,B) and temperature (Figures 2C,D) in coral hosts and their dinoflagellate endosymbionts. Indeed, no protein was differentially concentrated across temperatures in both $P$. acuta and Symbiodiniaceae. Photosynthesis and chloroplast-related processes were the functions most likely to be affected by host life stage (Figure 2B) and high-temperature exposure (Figure 2D and Table 1) in the dinoflagellates. Others have found Symbiodiniaceae photosynthesis proteins to undergo changes in concentration in response to elevated temperature exposure (Takahashi et al., 2008; Hoogenboom et al., 2012). In the coral

\section{Up-regulated in control treatment}

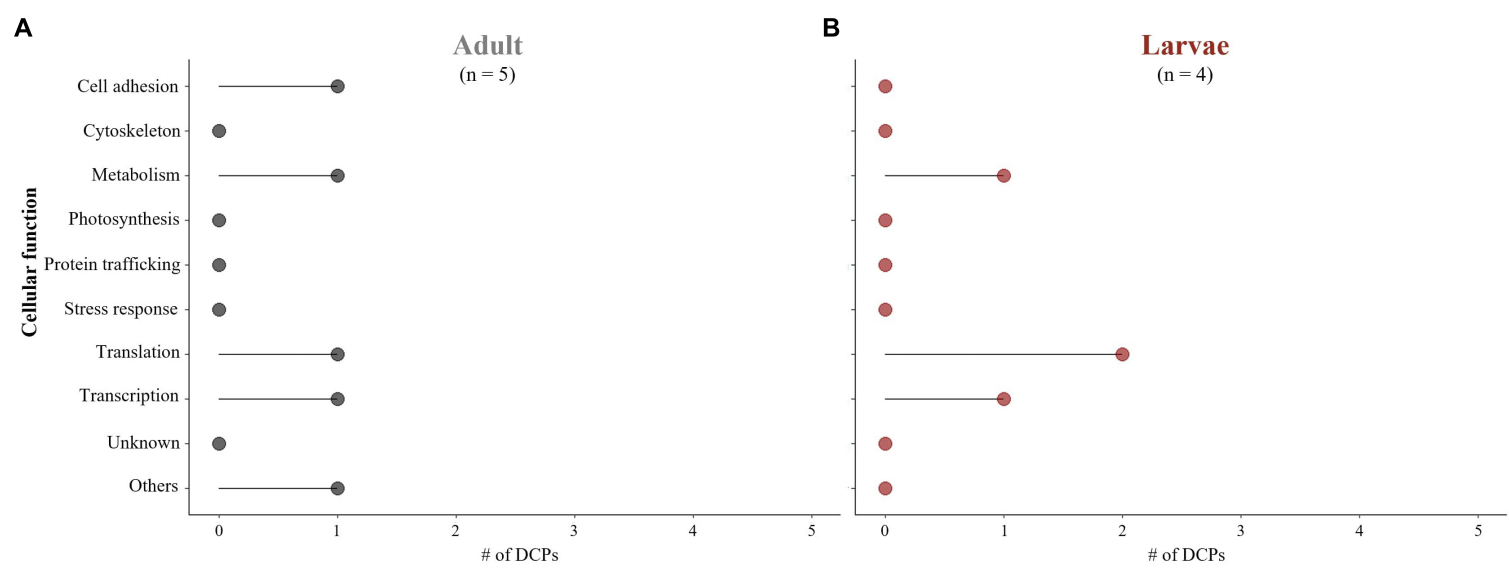

\section{Up-regulated in heated treatment}
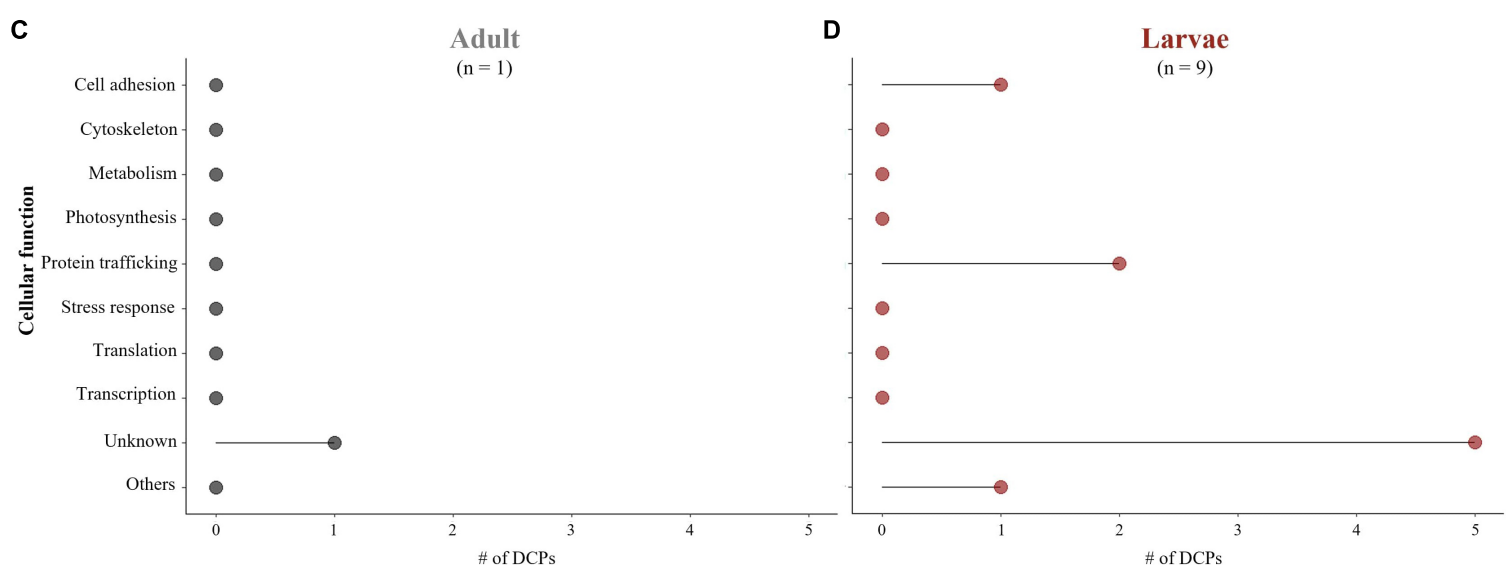

FIGURE 3 | Comparison of differentially concentrated proteins (DCPs) and their associated cellular function in Pocillopora acuta adults $(\mathbf{A}, \mathbf{C})$ and larvae (B,D); (A,B) DCPs up-regulated in the control treatment; (C,D) DCPs up-regulated in the heated treatment. 
hosts, protein trafficking and translation were the pathways most impacted by high-temperature exposure (Figure 2C), as also documented in thermally challenged sea anemones (Oakley et al., 2017).

Whereas only adult corals were manipulated in earlier projects, we had the opportunity to compare the proteomic responses of adult corals and their larval offspring in this study. Not only did the larval proteomes change more dramatically upon high-temperature exposure than those of their parents, but different proteins were affected as well (Figures 3A-D); only three of the 16 temperature-responsive proteins showed a congruent response between life stages (Table 1). Furthermore, the aforementioned high-temperature induction of proteins involved in protein trafficking was mainly attributed to the larval response alone (Figures 3B,D). Collectively, the observations that the protein-level responses to sub-lethal, high-temperature exposure differ between (1) host corals and their endosymbionts and (2) adult and larval corals highlight the need to consider both the holobiont response and life stage when assessing coral resistance and resilience in a warming ocean. Given the low level of replication in our study, we recommend a future analysis of additional samples to more rigorously elucidate the effects of temperature on the meta-proteome of this model coraldinoflagellate endosymbiosis.

\section{DATA AVAILABILITY STATEMENT}

All data within this manuscript can be found on the University of California San Diego's "MassIVE" repository (accession

\section{REFERENCES}

Barshis, D. J., Ladner, J. T., Oliver, T. A., Seneca, F. O., Traylor-Knowles, N., and Palumbi, S. R. (2013). Genomic basis for coral resilience to climate change. Proc. Natl. Acad. Sci. U.S.A. 1101, 1387-1392. doi: 10.1073/pnas.12102 24110

Bellworthy, J., Menoud, M., Krueger, T., Meibom, A., and Fine, M. (2019). Developmental carryover effects of ocean warming and acidification in corals from a potential climate refugium, the Gulf of Aqaba. J. Exp. Biol. 222:jeb186940. doi: 10.1242/jeb. 186940

Carballo-Bolaños, R., Denis, V., Huang, Y. Y., Keshavmurthy, S., and Chen, C. A. (2019). Temporal variation and photochemical efficiency of species in Symbiodinaceae associated with coral Leptoria phrygia (Scleractinia; Merulinidae) exposed to contrasting temperature regimes. PLoS One. 14:e0218801. doi: 10.1371/journal.pone.0218801

Cunning, R., Bay, R. A., Gillette, P., Baker, A. C., and Traylor-Knowles, N. (2018). Comparative analysis of the Pocillopora damicornis genome highlights role of immune system in coral evolution. Sci. Rep. 8:16134. doi: 10.1038/s41598-01834459-8

Fan, T. Y., Hsieh, Y. C., Lin, K. H., Kuo, F. W., Soong, K., McRae, C. J., et al. (2017). Plasticity in lunar timing of larval release of two brooding pocilloporid corals in an internal tide-induced upwelling reef. Mar. Ecol. Prog. Ser. 569, 117-127. doi: $10.3354 /$ meps 12071

Hoegh-Guldberg, O., Poloczanska, E. S., Skirving, W., and Dove, S. (2017). Coral reef ecosystems under climate change and ocean acidification. Front. Mar. Sci. 4:158. doi: 10.3389/fmars.2017.00158

Hoogenboom, M. O., Campbell, D. A., Beraud, E., DeZeeuw, K., and FerrierPagès, C. (2012). Effects of light, food availability and temperature stress on the function of photosystem II and photosystem I of coral symbionts. PLoS One 7:e30167. doi: 10.1371/journal.pone.0030167
\#MSV000087874), as well as the Proteome Xchange repository (accession \#PXD027523).

\section{AUTHOR CONTRIBUTIONS}

CJM, TYF, WBH, and IMC conceived the experiment. CJM performed the experiment. ABM conducted the lab work. ABM and CJM undertook the data analysis. ABM, CJM, and IMC wrote the manuscript in consultation with TYF and WBH. All authors contributed constructive feedback throughout the experiment and manuscript preparation.

\section{FUNDING}

This work was funded in part by charitable, crowd-sourced contributions to the Friendly Bear Editorial Service, as well as a grant from the Taiwan Ministry of Science and Technology to TYF (107-2611-M-291-004).

\section{SUPPLEMENTARY MATERIAL}

The Supplementary Material for this article can be found online at: https://www.frontiersin.org/articles/10.3389/fmars. 2021.716124/full\#supplementary-material

Keshavmurthy, S., Meng, P. J., Wang, J. T., Kuo, C. Y., Yang, S. Y., Hsu, C. M., et al. (2014). Can resistant coral-Symbiodinium associations enable coral communities to survive climate change? A study of a site exposed to long-term hot water input. PeerJ 2:e327. doi: 10.7717/peerj.327

Klepac, C. N., and Barshis, D. J. (2020). Reduced thermal tolerance of massive coral species in a highly variable environment. Proc. Royal Soc. B 287:20201379. doi: $10.1098 /$ rspb.2020.1379

Kohzuma, K., Froehlich, J. E., Davis, G. A., Temple, J. A., Minhas, D., Dhingra, A., et al. (2017). The role of light-dark regulation of the chloroplast ATP synthase. Front. Plant Sci. 8:1248. doi: 10.3389/fpls.2017.01248

Lee, H. J., Chao, S. Y., Fan, K. L., Wang, Y. H., and Liang, N. K. (1997). Tidally induced upwelling in a semi-enclosed basin: Nan Wan Bay. J. Oceanogr. 53, 467-480. doi: 10.1006/ecss.1999.0524

Mayfield, A. B., Chan, P. H., Putnam, H. P., Chen, C. S., and Fan, T. Y. (2012). The effects of a variable temperature regime on the physiology of the reef-building coral Seriatopora hystrix: results from a laboratory-based reciprocal transplant. J. Exp. Biol. 215, 4183-4195. doi: 10.1242/jeb.071688

Mayfield, A. B., Chen, Y. J., Lu, C. Y., and Chen, C. S. (2018). The proteomic response of the reef coral Pocillopora acuta to experimentally elevated temperature. PLoS One 13:e0192001. doi: 10.1371/journal.pone.0192001

Mayfield, A. B., Fan, T. Y., and Chen, C. S. (2013). Physiological acclimation to elevated temperature in a reef-building coral from an upwelling environment. Coral Reefs 32, 909-921. doi: 10.1007/s00338-013-1067-4

Mayfield, A. B., Wang, L. H., Tang, P. C., Hsiao, Y. Y., Fan, T. Y., Tsai, C. L., et al. (2011). Assessing the impacts of experimentally elevated temperature on the biological composition and molecular chaperone gene expression of a reef coral. PLoS One 6:e26529. doi: 10.1371/journal.pone.0026529

Mayfield, A. B., Wang, Y. B., Chen, C. S., Chen, S. H., and Lin, C. Y. (2014). Compartment-specific transcriptomics in a reef-building coral exposed to elevated temperatures. Mol. Ecol. 23, 5816-5830. doi: 10.1111/mec.12982 
McRae, C. J., Huang, W. B., Fan, T. Y., and Côté, I. M. (2021). Effects of thermal conditioning on the performance of Pocillopora acuta adult coral colonies and their offspring. Coral Reefs doi: 10.1007/s00338-021-02123-9

Oakley, C. A., Durand, E., Wilkinson, S. P., Peng, L., Weis, V. M., Grossman, A. R., et al. (2017). Thermal shock induces host proteostasis disruption and endoplasmic reticulum stress in the model symbiotic cnidarian Aiptasia. J. Proteome Res. 16, 2121-2134. doi: 10.1021/acs.jproteome.6b 00797

Putnam, H. M., Mayfield, A. B., Fan, T. Y., Chen, C. S., and Gates, R. D. (2013). The physiological and molecular responses of larvae from the reef-building coral Pocillopora damicornis exposed to near-future increases in temperature and pCO2. Mar. Biol. 160, 2157-2173. doi: 10.1007/s00227-012-2129-9

Putnam, H. M., and Gates, R. D. (2015). Preconditioning in the reef-building coral Pocillopora damicornis and the potential for trans-generational acclimatization in coral larvae under future climate change conditions. J. Exp. Biol. 218, 2365-2372. doi: 10.1242/jeb.123018

Putnam, H. M., Ritson-Williams, R., Cruz, J. A., Davidson, J. M., and Gates, R. D. (2020). Environmentally-induced parental or developmental conditioning influences coral offspring ecological performance. Sci. Rep. 10:13664. doi: 10. 1038/s41598-020-70605- $x$

Safaie, A., Silbiger, N. J., McClanahan, T. R., Pawlak, G., Barshis, D. J., Hench, J. L., et al. (2018). High frequency temperature variability reduces the risk of coral bleaching. Nat. Commun. 9:1671. doi: 10.1038/s41467-01804074-2

Shoguchi, E., Shinzato, C., Kawashima, T., Gyoja, F., Mungpakdee, S., Koyanagi, R., et al. (2013). Draft assembly of the Symbiodinium minutum nuclear genome reveals dinoflagellate gene structure. Curr. Biol. 23, 1399-1408. doi: 10.1016/j. cub.2013.05.062

Takahashi, S., Whitney, S., Itoh, S., Maruyama, T., and Badger, M. (2008). Heat stress causes inhibition of the de novo synthesis of antenna proteins and photobleaching in cultured Symbiodinium. Proc. Natl. Acad. Sci. U.S.A. 105, 4203-4208. doi: 10.1073/pnas.0708554105

van Oppen, M. J., Oliver, J. K., Putnam, H. M., and Gates, R. D. (2015). Building coral reef resilience through assisted evolution. Proc. Natl. Acad. Sci.U.S.A. 112, 2307-2313. doi: 10.1073/pnas.1422301112

Conflict of Interest: The authors declare that the research was conducted in the absence of any commercial or financial relationships that could be construed as a potential conflict of interest.

Publisher's Note: All claims expressed in this article are solely those of the authors and do not necessarily represent those of their affiliated organizations, or those of the publisher, the editors and the reviewers. Any product that may be evaluated in this article, or claim that may be made by its manufacturer, is not guaranteed or endorsed by the publisher.

Copyright (C) 2021 McRae, Mayfield, Huang, Côté and Fan. This is an open-access article distributed under the terms of the Creative Commons Attribution License (CC BY). The use, distribution or reproduction in other forums is permitted, provided the original author(s) and the copyright owner(s) are credited and that the original publication in this journal is cited, in accordance with accepted academic practice. No use, distribution or reproduction is permitted which does not comply with these terms. 